\title{
Four challenges facing newly elected climate chief
}

\section{New leader of Intergovernmental Panel on Climate Change, Hoesung Lee, has a full in-tray.}

\section{Quirin Schiermeier \& Jeff Tollefson}

06 October 2015

South Korean economist Hoesung Lee, a professor at the Korea University in Seoul, was elected as the fourth chair of the Intergovernmental Panel on Climate Change (IPCC) on 6 October during a meeting in Dubrovnik, Croatia. He previously served as a vice-chair of the IPCC.

Lee, who beat out several candidates for the panel's top job, has said that he wants the IPCC to focus on "policy relevance and neutrality", to increase participation by experts from developing nations and to explore ways to involve business and industry in the IPCC process.

Since 1990, the IPCC has conducted five major assessments of the science of climate change, as well as mitigation and adaptation strategies to cope with global warming. Thousands of researchers, most from the natural sciences and economics, have volunteered their time to compile these comprehensive reports.

The group's labours earned it a share of the 2007 Nobel Peace Prize. But the IPCC has also stumbled in recent years; its 2007 report erroneously stated that Himalayan glaciers are likely to disappear by 2035 . And its last chairman, Indian economist Rajendra Pachauri, resigned in February amid allegations of sexual harassment.

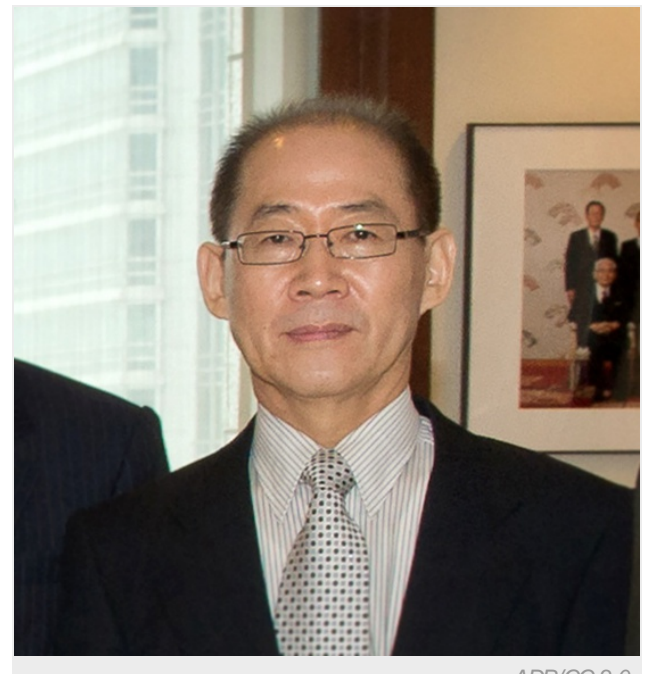

$A D B / C C 2.0$

Hoesung Lee is a former IPCC vice-chair.

Nature examines some of the major challenges facing the IPCC and its new chief.

\section{Becoming more nimble}

Critics say that the IPCC risks losing relevance if it does not become more agile; over time, the group's reports have grown longer, and the time that it takes to prepare them has increased. Whether, and how, to reform the IPCC has been debated for several years.

Michael Oppenheimer, who studies geosciences and international climate policy at Princeton University in New Jersey, argues that a shift to shorter reports on pressing issues may be a greater aid to lawmakers and others interested in climate policy. On his wish list: a special report on the state of the world's ice sheets and projections of sea-level rise.

"Communities are making decisions on coastal protection every day," says Oppenheimer. "Here's an issue where guidance from the IPCC would be really in demand."

But a sweeping reorganization of the group is not on the radar. After an internal review, the IPCC decided earlier this year to continue to prepare comprehensive assessment reports, supplemented by occasional special reports on specific aspects of climate change.

\section{Joining forces with social scientists}

Scientific and economic reasoning is an adequate way to frame the climate problem — but it is by no means the only way, says Matthew Nisbet, a communication and policy specialist at Northeastern University in Boston, Massachusetts.

$\mathrm{He}$ is among the IPCC watchers who argue that the group should incorporate more insights from the social sciences in its climate reports. Increasing input from sociologists, psychologists, anthropologists and political scientists can help scientists and policymakers understand how climate information is perceived, trusted and used by governments and private industry.

"The more severe the [climate-change] problem becomes the more it will polarize societies," says Nisbet. "You're just not going to reach a threshold where everybody agrees that the IPCC is right. This will never happen." 
The IPCC has decided to open itself to research by social scientists who are seeking to understand how the organization works. Oppenheimer is a member of one team that has already requested access to the group's internal deliberations. With new leadership in place, Oppenheimer says that he expects the IPCC to establish rules and procedures that will enable the research to move forward during the next assessment.

\section{Building bridges to the developing world}

Fewer than one-third of the more than 830 authors involved in the IPCC's latest assessment are from Africa, Asia and South America. That mirrors the demography of science, but it means that some of the countries that are likely to suffer most from the impacts of climate change have the least representation on the science panel.

"The new chair needs to ensure that more scientists from developing countries are included in future assessment reports," says Saleemul Huq, director of the International Centre for Climate Change and Development in Dhaka, Bangladesh.

The challenge, however, is to reconcile equity and excellence. National academies in North America and Europe — where most IPCC authors come from - need to engage more in training researchers from developing countries, says Ottmar Edenhofer, a previous cochair of the IPCC's climate-mitigation group. "Geographical balance and regional perspective are vital things," he says. "But first and foremost the IPCC must seek to keep up its standard."

\section{Learning to speak in plain English}

IPCC language is often barely comprehensible for non-scientific audiences. Here is an example of text from a 2014 summary for policymakers:

"The emission scenarios collected for this assessment represent full radiative forcing including GHGs, tropospheric ozone, aerosols and albedo change. Baseline scenarios (scenarios without explicit additional efforts to constrain emissions) exceed 450 parts per million (ppm) CO2eq by 2030 and reach CO2eq concentration levels between 750 and more than 1300 ppm CO2eq by 2100 . This is similar to the range in atmospheric concentration levels between the RCP 6.0 and RCP 8.5 pathways in 2100."

The habit of packing scientific and technical jargon into long sentences drives any reader away, says Suraje Dessai, an environmental social scientist at the University of Leeds, UK, who has compared the readability of IPCC reports with that of news reports on climate science from general and scientific media. His analysis showed that the IPCC stands out for its low readability.

The public and policymakers, says Dessai, would be much better served if the IPCC were able to communicate findings in simpler language. "People might then go straight to the source rather than to media which tend to charge climate news with sentiment," Dessai says.

To improve the readability of its works, the IPCC plans to seek advice from communication specialists.

Nature I doi:10.1038/nature.2015.18492 